\title{
The Effects of Reading and Language Intervention on Literacy Skills in Children in a
}

\section{Remote Community: A Randomized Controlled Trial}

Carol Mesa ${ }^{1 *}$, Dianne F. Newbury ${ }^{2}$, Marysia Nash $^{3}$, Paula Clarke ${ }^{4}$, Rosanne Esposito $^{5}, Z_{\text {Zulema }}$

De Barbieri ${ }^{6}$, Ma. Angélica Fernández ${ }^{6}$, Pia Villanueva ${ }^{6}$, Charles Hulme $^{7}$, Margaret J.

$$
\text { Snowling } 1,3 *
$$

1: Department of Experimental Psychology, University of Oxford, Oxford, UK, OX2 6HG;

2: Department of Biological and Medical Sciences, Oxford Brookes University, Oxford, UK, OX3 0BP;

3: Department of Experimental Psychology and St John's College, University of Oxford, Oxford, UK, OX1 3JP;

4: School of Education, University of Leeds, Leeds, UK, LS2 3AR;

5: Institute of Education, University College London, London, UK, WC1H 0AL;

6: Departamento de Fonoaudiología, Universidad de Chile, Santiago, Chile;

7: Department of Education, University of Oxford, Oxford, UK, OX2 6PY;

* - these authors contributed equally to this work

Correspondence concerning this article should be addressed to Prof Margaret Snowling, Department of Experimental Psychology, University of Oxford, Oxford, UK, OX2 6HG, +44

1865 277419. E-mail: maggie.snowling@sjc.ox.ac.uk

Running Head: A Reading and Language Intervention 


\begin{abstract}
This study evaluated the effects of a reading and language intervention, for low-income children living in a remote Chilean community, using a randomized controlled trial. At the beginning of the study, participants were allocated to the intervention $(n=34)$ or waiting control $(n=34)$ minimizing on a composite language measure and age. Children in the intervention group received a 27 -week program aimed at fostering code-related, word reading and oral language skills. Children's progress in language and literacy was monitored at four time points: pre-, midpost-intervention, and at delayed follow-up 9-months after the intervention had ceased. At the end of the intervention, children in the intervention group scored showed improvements compared to the waiting group on pre-literacy, reading, language, and reading comprehension measures (effect sizes $d>.25$ ). The gains in pre-literacy skills, word reading and word knowledge were maintained at 9-month delayed follow-up, though the improvements in language and reading comprehension were not. Intervention programs designed to support literacy and language skills in remote communities can be delivered successfully by trained assistants. Our findings inform the future provision of language and literacy programs in populations living in isolated areas.
\end{abstract}

Keywords; reading and language intervention, remote community, RCT 
The United Nations Sustainable Developments Goals (2019) state that 'obtaining a quality education is the foundation to creating sustainable development' (SDG4 https://www.un.org/sustainabledevelopment/education/). Further, while many millions of youth worldwide lack basic literacy skills, the goals recognize that 'bolder efforts are needed to make even greater strides for achieving universal education'. The present study was conceived within this broad framework in an attempt to improve literacy in a remote and vulnerable community.

Language skills form the cornerstone of educational achievement and children who enter school with poor language and reading skills typically struggle in the classroom. We know that structured, multi-component intervention programs can help to ameliorate some of these difficulties (Whitehurst \& Lonigan, 1998). However, there is a dearth of evidence about 'what works' for literacy instruction in communities with differing cultural backgrounds from those largely English-speaking communities for which the programs have been designed (Bekman, Aksu-Koç, \& Erguvanl1-Taylan, 2011; Nag, Chiat, Torgerson, \& Snowling, 2014; Opel, Ameer, \& Aboud, 2009). It is widely reported that socioeconomic status is correlated with reading ability in early school grades and that rural, indigenous populations are "vulnerable" to literacy failure (LAC Reads Capacity Program, 2016). The reasons underlying this vulnerability are complex and the specific circumstances are usually unique to a given population. Nonetheless, there are contextual challenges that are typically found in many such communities. These include geographic factors (which can limit the delivery of materials and accessibility to education), demographic influences (including social and economic disadvantages and differences in expectations), educational settings (which may have to be adapted to allow for vulnerabilities) and social isolation. It is important to understand the impact that these factors 
can have upon the "real-world" delivery of intervention programs to such vulnerable communities.

In this study, we develop and deliver a reading and language intervention program to a small isolated community in South America. The program was built upon evidence-based practices and successful intervention methods from Western cultures (Foorman, Breier, \& Fletcher, 2003; McCardle \& Chhabra, 2004; National Reading Panel, 2000), with appropriate content and structural adaptations to material. The principles of the program were derived from the 'Simple View of Reading' (Gough \& Tunmer, 1986) and drew on longitudinal data that suggests causal links between language as a foundation for literacy, mediated by phonological awareness and decoding skill, and a direct impact of oral language skills on reading with comprehension (Hulme, Nash, Gooch, Lervag, \& Snowling, 2015; Lervåg, Hulme, \& MelbyLervåg, 2018). Accordingly we trained decoding skills; letter-sound knowledge and phonological awareness in the context of graded book reading following the strategies of an established UK program (Hatcher, Hulme, \& Ellis, 1994), alongside language comprehension; vocabulary and narrative skills, and reciprocal reading strategies following Clarke et al. 2010 (Clarke, Snowling, Truelove, \& Hulme, 2010). We hypothesized that the theoretical grounding of the program would facilitate successful gains in literacy even in challenging contexts. Our study therefore aims to add to the literature regarding "what-works" in the use of educational intervention programs in vulnerable communities (Kremer, Brannen, \& Glennerster, 2013; Nag et al., 2014).

\section{Theoretical Framework}

In devising the program, we took account of a number of key principles concerning effective literacy and reading instruction (Carroll, Bowyer-Crane, Duff, Hulme, \& Snowling, 
2011; National Reading Panel, 2000). Our starting framework consisted of the Simple View of Reading (Gough \& Tunmer, 1986), which proposes that the ability to understand written text relies upon both "decoding", which facilitates links between text and sound, and "language comprehension", which is critical for reading with meaning and which has proven a strong framework for the development of effective teaching and intervention programs for both typically developing and language-impaired children (reviewed by Stahl \& Fairbanks, 1986). Importantly, learning to decode is a crucial step in the process of learning to read and weaknesses in decoding skills are an obstacle to reading comprehension (Castles, Rastle, \& Nation, 2018). Conversely, strong decoding skills allow the effective application of language comprehension within a multiplicative model, enabling advanced levels of text processing, such as making inferences (Cain \& Oakhill, 1999). These predictions are supported by longitudinal studies, in which decoding predicts early growth of reading comprehension while the relationship between for oral language and reading comprehension strengthens in older children (e.g. García \& Cain, 2014; Quinn, Wagner, Petscher, \& Lopez, 2015), and through the success of teaching programs that support reading development through instruction in both vocabulary and decoding (Duff \& Clarke, 2011). Importantly too, these findings appear to be universal across alphabetic languages (Norwegian (e.g. Høien-Tengesdal \& Høien, 2012), Swedish (e.g. HøienTengesdal, 2010), French (e.g. Megherbi, Seigneuric, \& Ehrlich, 2006) ,Spanish-speakers in the USA (e.g. Joshi, Tao, Aaron, \& Quiroz, 2012), Italian (e.g. Tobia \& Bonifacci, 2015) and Finnish (e.g. Torppa et al., 2016)), as well as in languages that use non-alphabetic writing systems (Chinese (e.g. Hulme, Zhou, Tong, Lervåg, \& Burgoyne, 2019; Joshi et al., 2012)) However, despite the longstanding influence of the Simple View, the idea that the bipartite effects of decoding and language comprehension can explain reading comprehension is 
considered as overly-simplistic by some (Francis, Kulesz, \& Benoit, 2018). A primary area of debate regards the use of these two terms; what they encapsulate and the best way to accurately measure them. Decoding is often measured by nonword reading skill but it is widely accepted that, in addition to translating between letters and sounds, phonological awareness is important, as are processes such as word recognition and reading fluency. Naming skills are also strong predictors of individual differences in this component (Nation, 2019). Similarly, vocabulary knowledge is often considered as a proxy for the language comprehension component although inferential skills, working memory and syntax are also involved (Kim, 2017). In fact, Lervåg et al. (2018) showed that the language comprehension component can be represented by the shared effects of vocabulary, syntax, morphology, verbal working memory and inference, represented as a single latent factor, rather than by the unique effects of each of these factors independently. A further study from the same group indicated that decoding can be captured by phoneme awareness, letter knowledge and rapid naming but is also influenced by early oral language skills (Hjetland et al., 2018). These studies therefore imply that within the simple-view framework, the terms decoding and language comprehension each represent multifaceted processes that encapsulate a range of relevant skills necessary for the development of proficient reading.

In addition, reading skills require motivation and depend upon practice outside of the classroom, where engagement with a range of different texts is likely to play a role (van Bergen et al., 2018). Similarly, teacher and parent expectations, demographic factors (including the home environment, Dilnot, Hamilton, Maughan, \& Snowling, 2017) and dialect differences are all factors that will affect literacy outcomes (Aaron, Joshi, Gooden, \& Bentum, 2008; Francis et al., 2018; Nag, Snowling, \& Asfaha, 2016). In short, the simple view underestimates individual 
differences and dispositions which children bring to the task of reading, and these are likely to play an important role when delivering reading interventions to vulnerable communities.

Although the simple-view of reading appears to account well for individual differences across languages including European (Caravolas et al., 2019; Florit \& Cain, 2011) and Latin American Spanish (LAC Reads Capacity Program, 2016), the general view is that decoding is easily acquired by Spanish children. However, of particular relevance to the current study, is that children with language learning impairments may nonetheless struggle with basic decoding as well as with reading comprehension processes (Bishop \& Snowling, 2004). In addition, in vulnerable populations, baseline skills may differ from expected, demographic differences are inflated, education may not be prioritized and engagement may require adaptations. Moreover, intervention programs that target social, emotional and environmental factors have been shown to have small but positive effects upon reading attainment and vocabulary in vulnerable populations (Corcoran, Cheung, Kim, \& Xie, 2018; Leyva \& Skorb, 2017). Together these finding underscore the inter-dependence of environmental and educational factors and support the idea that a multi-componential and holistic approach is required when delivering reading intervention programs to vulnerable populations.

\section{The study population}

The current study involves the Spanish-speaking community of the Robinson Crusoe Island, situated $600 \mathrm{~km}$ to the West of mainland Chile. We focus upon this population because it is geographically and socially isolated and is reported to have an unusually high incidence of language disorders (De Barbieri, Fernandez, Newbury, \& Villanueva, 2018). Difficulties are reported across a range of linguistic measures including phonological production and expressive and receptive morphology (De Barbieri et al., 2018). Further, the language difficulties observed 
in this population aggregate within families from the last island colonization which suggests the influence of genetic risk factors (Villanueva et al., 2015), although the contributory genetic mechanisms have yet to be fully characterized (Mountford et al., 2019).

People in Robinson Crusoe Island live in a single town and, except for a few children who are home-schooled, all children attend the same school in which Spanish is the language of instruction. Since a tsunami in 2010 , the school has been housed in shipping containers with limited light and ventilation and poor conditions for teaching; since access to the island (and the internet) is difficult, this further restricts provisions for a high-quality education. Added to this, travel to the mainland for medical and dental treatment can affect regular school attendance.

\section{The Teaching of Reading Skills in Latin America}

Beyond its theoretical grounding, at least two sets of macro-environmental factors need to be taken into account when considering the design and implementation of an intervention: the home and school language of the community and the prevailing educational policy within which schools operate. In 2006, the Chilean Government announced the "Chile Crece Contigo" program aimed at providing essential early childhood services in deprived areas. Three primary areas of support were identified: language and literacy development, classroom behavior management and improved coordination between early childhood education and health care (Peralta, 2011). Since then, new teacher-training strategies have been introduced; however, school systems practice freedom in curricula activities meaning that these new skill sets are not always put into practice regularly (Yoshikawa et al., 2015)

Traditionally in Latin America, reading is taught solely through the school system and is considered a mechanical skill. Such teaching strategies remain in many Chilean schools where children are taught to read through rote learning, and where reading fluency is considered a 
proxy of comprehension. Sound-letter linkages are not explicitly taught and the teaching of reading focuses upon language structure (grammar) and memorization methods (Ponce, López, \& Mayer, 2012). Children are encouraged to read stories aloud with little focus upon context, inference or meaning and opportunities for book sharing, dialogic interaction and group work are limited (Strasser, Mendive, Vergara, \& Darricades, 2018). Thus, almost paradoxically, while story-telling represents a central ethos on the island, engagement with written text is low.

Chilean law requires at least one adult per 16 children in a kindergarten classroom, with a maximum class size of 32 children. The adults may be teachers or could be teaching assistants (Strasser et al., 2018). The school on the island follows the Mainland curriculum and rules but due to space constraints, has mixed-age classrooms. All lessons are given in Chilean Spanish and this is the native language of all inhabitants enrolled in this study.

\section{Reading Intervention Studies in Latin America}

There are few intervention studies involving monolingual Spanish-speaking children in Latin America (LAC Reads Capacity Program, 2016). Given that Spanish is a transparent language, it is perhaps counterintuitive that most have emphasized the teaching of letter knowledge and phonological awareness rather than oral language skills (e.g. Flórez-Romero, Restrepo, \& Schwanenflugel, 2009; San Francisco, Arias, Villers, \& Snow, 2006). The majority of previous interventions programs in Chile focus upon teacher training practices and evaluate outcomes of a government-sponsored program in mainland Chile (Gomez Franco, 2014; Mendive, Weiland, Yoshikawa, \& Snow, 2016; Yoshikawa et al., 2015). These studies report positive impacts for the teachers who received training in vocabulary, oral production, comprehension, and writing teaching methods. However, no significant effects were found in terms of any of the student outcomes evaluated (Gomez Franco, 2014; Mendive et al., 2016; 
Yoshikawa et al., 2015). The authors observed that although teachers were competent and engaged with the program, their delivery may be limited by factors that prevent consistent and automatic presentation within the classroom setting. Accordingly, they subsequently introduced a teacher checklist to encourage self-monitoring behaviors (Strasser et al., 2018). While the checklist did increase the frequency with which teachers applied target language tasks in the classroom (such as shared reading, taught vocabulary use, discussion of books), no significant effects were found upon child oral language (Strasser et al., 2018). The authors suggest that extra training may be required to provide the teachers with additional strategies (Strasser et al., 2018). Notwithstanding this, Pallante and Kim (2015) found that a teacher training program, which targeted phonology, fluency, vocabulary, writing and reading comprehension produced only small effects upon reading in kindergarten and first-grade children $(\mathrm{SMD}=0.16,95 \% \mathrm{CI}=-$ 0.17-0.48) (Pallante \& Kim, 2013). In contrast, although the sample size was small, Larrain, Strasser and Lissi (2012) found that word elaboration and explicit vocabulary training as part of shared reading had positive effects upon vocabulary acquisition (Larraín, Strasser, \& Lissi, 2012).

Finally two studies made use of technology to facilitate intervention. Ponce et al. (2012) trialed a computer-based program that taught reading strategies to support language comprehension across 21 schools (both municipal and private) in Central Chile (Ponce et al., 2012). They found gains $(d=0.5)$ that were highest for those children who started the program with the lowest reading ability. However, although some rural schools were included in the study, only one population was classified as having low socioeconomic status (Ponce et al., 2012). Rosas et al. (2017) also used computer-based methods within a phonological training game (GraphoGame), in low-school achievers in mainland Chile. There was a direct effect of 
the program upon knowledge of letter-sound linkage but this did not generalize to reading comprehension (Rosas, Escobar, Ramírez, Meneses, \& Guajardo, 2017).

In short, some positive effects of interventions for Chilean children have been reported though most studies focus upon a single aspect of reading-related skills rather than the multiple components highlighted by the theoretical framework of the simple view of reading.

Furthermore, few studies include vulnerable communities and many are reported to have selection biases or flawed experimental designs (LAC Reads Capacity Program, 2016). The majority focused upon a single reading outcome measure with no distinction between decoding, reading skills and language (LAC Reads Capacity Program, 2016). There is therefore a clear need for additional high-quality research on the application of evidence-based intervention programs in vulnerable communities. Information regarding the portability of evidence-based interventions is critical to scale-implementation in developing countries and, as such, is relevant to the Sustainable Development Goals (SDGs) of the United Nations; 'to employ creative and innovative solutions in order to change the course of education and raise educational standards'.

\section{Aims of the current study}

The current study used the simple-view framework as a basis for the design of intervention programs for vulnerable communities. To this end, we designed and applied a 27week multi-component intervention program on the Robinson Crusoe Island in Chile. We named the intervention program the "Chilean Language And Reading Alliance - CLARA". CLARA incorporated training of letter-sound knowledge and phonological awareness (e.g. Catts, Herrera, Nielsen, \& Bridges, 2015) in the context of graded book reading as described by Hatcher et al. (Hatcher et al., 1994) with training in vocabulary (e.g. Catts et al., 2015), narrative skills (e.g. Griffin, Hemphill, Camp, \& Wolf, 2004; Justice et al., 2006), and reading strategies 
that allow the reader to build text understanding beyond literal interpretation (e.g. Duke, Pearson, Strachan, \& Billman, 2011; Hogan, Bridges, Justice, \& Cain, 2011; Perfetti, Landi, \& Oakhill, 2005) as described by Clarke et al. (Clarke et al., 2010). We took account of the cultural context when considering the issue of implementation and included specific advice to the tutors who delivered the program. CLARA was delivered within a school setting by four resident tutors who were given appropriate training in the teaching methods and were required to document lesson plans and pupil progress. The efficacy of the intervention was evaluated using a randomized controlled trial in accordance with the CONSORT guidelines. We predicted that children who received the intervention would show stronger reading and language skills than those in the waiting list arm of the trial. We also hypothesized that gains in these skills would mediate gains in reading comprehension, in line with the predictions of the Simple View of Reading. In addition, we explored longer term outcomes at follow-up after 9 months.

\section{Methods}

\section{Participants}

The entire child population of the island (132 children), aged 4-14 years, were eligible for the study. Sample size was limited by total population size. Following attendance at information sessions, parents of 78 children gave signed consent for their child to take part and were enrolled by the first author. Ten of the children then relocated to another island leaving a final sample of 68 children (Figure 1). Ethical approval was granted by Oxford University Research Ethics Committee (R42391/RE001).

Demographic information was collected from parents of participants through a questionnaire. Information is presented here to describe and contextualize the cohort (but was not used in the analyses). On average, participant children spent six weeks of the year on the 
Mainland, usually during the school holidays. Twenty eight percent of participants had special educational needs which warranted an individual learning plan at school. Twenty six percent of caregivers reported that their child had a reading difficulty and five percent reported a language difficulty. These individuals were evenly spread across the intervention and waiting control groups (the differences in parental report for reading and language problems is typical, the latter being less easy to notice in a familiar family setting).

Thirty percent of participants had at least one parent who was born on the island. All but one child lived with their Mother or Father. All but one household included at least one working adult and an average of 1.8 children under the age of 18 (range 1-3). Ninety five percent of participants had at least one parent who completed high school. Thirty eight percent of participants had at least one parent who attended college and $7 \%$ had at least one parent with a higher education qualification. Ninety three percent of caregivers said that they thought being able to read was an important life skill.

We conducted a randomized controlled trial, with a cross-over design, in accordance with the CONSORT guidelines (Schulz, Altman, \& Moher, 2010) (Figure 1). Group allocation was conducted independently by the University of York Trials Unit. Sixty-eight participants completed pre-tests to assess language and reading ability. Participants were allocated to intervention (experimental) $(\mathrm{n}=34,17$ male, 17 female) or waiting (control) groups $(\mathrm{n}=34,17$ male, 17 female) minimizing for age and a composite score of pre-test language measures.

\section{<Figure 1 about here>}

\section{Measures}

The primary outcomes of the intervention were reading and language skills, while the secondary outcomes were reading comprehension and oral narrative. The study was designed to 
allow change to be detected in factors reflecting growth in pre-literacy, reading, and language skills with good reliability. Accordingly multiple tests were used to assess each construct (see below). All measures were collected pre- (t1) and post- (t3, 27 weeks after the start of intervention) intervention. Baseline measures of nonverbal IQ, recalling sentences and arithmetic ability were also collected. Additional assessments to monitor progress were performed at mid-test ( $\mathrm{t} 2,14$ weeks after the start of the intervention) and 9 months after the completion of intervention for the intervention group (t4); this was week 20 of the intervention for the waiting control group. A full list of measures taken at each time point and their reliabilities can be found in Table 1. Further details of tests are given below.

Where possible, assessments employed standardized Chilean or European Spanish measures. Test rubrics were adapted for the target population by Spanish Speakers from Chile. In some instances (vocabulary, reading comprehension), standardized tests were not available and assessments were translated from standardized English tests. Translated items were revised by three Spanish-speaking people and assessed for cultural suitability by an Islander. After translation, these tests were trialed in a group of 8 Spanish-speaking children and modifications were made as needed. Ten percent of the audio-recorded measurements (WISC vocabulary, bespoke vocabulary, listening comprehension, reading comprehension and story grammar) were double scored to obtain point-by-point percent of agreement allowing estimation of inter-rater agreement.

Assessments took two hours, over three sessions, and the order of tasks varied across participants. Assessors were blind to group allocation at $\mathrm{t} 1$ (pre-test) and $\mathrm{t} 3$ (post-test), and trained in test administration and scoring. All data entries were double checked, approximately $50-60 \%$ by the first author. 


\section{Basic Reading and Related Skills}

All reading tasks were taken from Caravolas et al. 2012, a longitudinal study of literacy development across four languages, including Spanish. In this previous study, all tasks were tested and standardized in 190 native Spanish speakers aged 61-73 months (Caravolas et al., 2012).

Letter knowledge. The task captured children's knowledge of sound and name letters. Twenty-nine Spanish letters (i.e., 27 letters and 2 digraphs) were assessed. The number of letters correct was summed to give measures of letter-name and letter-sound knowledge (Caravolas et al., 2012).

Phoneme awareness. This measure tested identification, deletion, blending and segmentation (Caravolas et al., 2012). The test consisted of 30 items at $\mathrm{t} 1$ and 60 items for the remaining administration points. The score represents the number of correct responses across the test. Testing was discontinued after four consecutive errors.

Word Reading. Two tasks were used to measure children's word reading. In the Picture Word Matching Reading Test (PWMRT), the child identifies the word that matches a target picture for as many words as possible in three minutes $(\max =63)$ (Caravolas et al., 2012). The score represents the number of correct target pictures identified in one minute. In the oneminute reading test, children must read as many words as possible from a list of 140 highfrequency Spanish words from two to five syllables (Caravolas et al., 2012). The score represents the number of correct words read in one minute.

Nonword reading. This task measured phoneme awareness and comprised 140 nonwords of between 2 and 5 syllables constructed to resemble Spanish word structure 
(Caravolas et al., 2012). The score represents the number of correct nonwords read in one minute.

Spelling. A spelling-to-dictation task measured children's word-spelling skills (Caravolas et al., 2012). Ten target words were dictated at t1, and 35 at later time-points. The score represents the number of words correctly spelt.

\section{Vocabulary}

One vocabulary measure (CELF-4) had been standardized in Spanish. The other two measures (WISC-IV and ROWPVT) were translated from tests developed and standardized on English-speaking children (as detailed below).

Expressive vocabulary. Children's expressive vocabulary was assessed using two subtests from the CELF-4 (Spanish version) and WISC-IV (English version) respectively. In the CELF-4 vocabulary subtest, children name a set of pictures (Semel, Wiig, Secord, \& Langdon, 2006). At $t 1$, twenty nine words were tested. After $t 1$, nine bespoke words were added to this original subtest to avoid ceiling effects. The scoring rubric allowed for dialectal differences and children received 2 points for correct definitions, 1 point for partial definitions, and 0 points for incorrect or unrelated definitions. Testing was discontinued after eight consecutive errors.

In the Wechsler Intelligence Scale for Children (WISC-IV) vocabulary subtest, children define a series of 36 words (Wechsler, 2003). Children received 2 points for correct definitions, 1 point for partial definitions, examples or correct use of the word in a sentence, and 0 points for incorrect or unrelated definitions. Testing was discontinued after six consecutive errors. Interrater agreement varied from 89 to $100 \%$ across cases.

Receptive vocabulary. Children's receptive vocabulary was assessed using the Receptive One-Word Picture Vocabulary Test (ROWPVT) translated from English to Spanish. In this test, 
the child points to the picture that best represents the stimuli word (Martin \& Brownell, 2012). One hundred pictures are provided and the starting point is determined by the child's age. The score represents the number of correct responses across the test.

Bespoke vocabulary. This experimental measure assessed children's ability to define words explicitly taught during the intervention. Children had to provide a definition for each of 21 target words. Responses were scored 2 points if the child provided a complete definition, 1 point if the child provided a partial response (e.g., incomplete definition, an example, or correct use of the word meaning in a sentence), and 0 points if the child's definition was incorrect or unrelated. Inter-rater agreement was $81-100 \%$.

\section{Narrative Skills}

Listening comprehension and narrative production were assessed using measures designed and standardized in Chile.

Listening comprehension. Children's listening comprehension was assessed with the Evaluación del Discurso Narrativo (EDNA; Guzmán, Tirapegui, \& Landaeta, 2012). This test was developed and standardized in Chile (Pavez, Coloma, \& Maggiolo, 2008). The assessor reads a short story after which the child is asked 10 comprehension questions. Responses were scored 2 points if the child provided a complete response, 1-point if the child provided a partial response or 0-points if the response was incorrect or unrelated. Inter-rater agreement was 90$100 \%$.

Narrative production. Children's narrative language was assessed using Procedimientos para Evaluar Discurso (PREDI). This test was developed and standardized in Chile (Pavez, Coloma, Maggiolo, Martínez, \& Romero, 2002). The assessor asks the child to arrange a picture sequence and tell a story about it. Children's stories were audio recorded, transcribed verbatim, 
and coded using Systematic Analysis of Language Transcripts (SALT) software (Chapman \& Miller, 1984). Using transcriptions, children's narratives were analyzed to generate three measures of narrative; story grammar, Mean Length of Utterance in words (MLU-w), and Subordination Index.

The measure of Story Grammar determined whether the child's narrative included key elements of Story Grammar (character, setting, problem, emotion, attempt, consequence and end). Each story element was scored as 2, 1 or 0. Inter-rater agreement was $71-100 \%$.

Mean Length of Utterance was the average of number of words per C-unit (a main clause or a main clause with all its subordinating clauses). This measure of child language complexity is reliable for Spanish speakers (e.g. Gutierrez-Clellen \& Hofstetter, 1994).

The subordination index is a measure of language complexity (total number of clauses divided by total number of utterances) (Heilmann, Miller, Nockerts, \& Dunaway, 2010).

\section{Reading comprehension.}

A Spanish translation of the York Assessment of Reading and Comprehension (YARC; Snowling et al., 2009) was used to measure reading comprehension as no Chilean Spanish measure was available. In this test, the child reads six short paragraphs aloud. After each paragraph, the assessor asked eight comprehension questions. Responses were scored 1-point if the child provided a correct response and 0-points if the response was incorrect. Inter-rater agreement ranged from $93-100 \%$ across stories.

\section{Cognitive and Control Measures}

Nonverbal ability (pre-test only). Children's nonverbal ability was assessed using the Raven's Progressive Matrices (test-retest reliability from .83 a .93 according to age (RAVEN; Raven \& Court, 1998). 
Recalling Sentences (pre-test only). The Recalling Sentences subtest from CELF-4 (Spanish version) evaluates the ability to repeat spoken sentences of increasing complexity (Semel et al., 2006).

Arithmetic (pre-test only). The Addition and Subtraction subtasks from Test of Basic Arithmetic and Numeracy Skills (TOBANS; Brigstocke, Moll, \& Hulme, 2016) assessed children's arithmetic ability.

\section{Principles of the Intervention}

CLARA aimed to improve literacy skills by promoting decoding skills and oral language comprehension and by linking these two facets of reading. It was designed to follow a highly structured and systematic format (so that pupils knew what to expect in each session) and to make use of multi-sensory techniques for the teaching of code-related elements and vocabulary. The general aim was to deliver an individualized program tailored to the specific needs of the individual children but involving small group work (usually dyads) to encourage interaction, particularly in relation to language learning. The program was manualized with detailed lesson plans; however tutors were trained to ensure that teaching was at an appropriate level, and for reading, in the proximal level of instruction to avoid despondency. Practice and reinforcement was embedded in the approach; teachers planned lessons using checklists, recorded pupil progress using running records for reading and narrative recordings for language and conducted more formal checks on emergent reading skills. Materials were based on existing intervention programs but were adapted to fit within the context of the community, choosing books and activities which were meaningful to participants and therefore engaging, using a variety of texts and genres.

\section{Intervention Program}


Children received four sessions a week following three formats; (1) a reading component that targeted basic reading skills, (2) a language component that supported vocabulary and narrative language, and (3) a reciprocal teaching component that promoted the use and understanding of reading strategies. At the start of the program, all children received three 20minute reading sessions and one 30-minute language session a week. At mid-test (t2, after 14 weeks of intervention), all children who were considered to have achieved decoding proficiency were introduced to the reciprocal teaching component, which was designed to reinforce reading comprehension skills through the promotion of independent metacognitive strategy use.

Decoding proficiency was defined as having secure letter knowledge 0.4SD and phonological awareness $0.25 \mathrm{SD}$ above the group mean and being able to read independently (with $94 \%$ accuracy) a book graded greater than 21 on a scale developed by (Hatcher et al., 1994) for this approach. For these children $(\mathrm{n}=19)$, the dose of all 3 components was rebalanced such that they received one 20-minute reading session, one 30-minute language session and two 30-minute reciprocal teaching sessions per week for the remainder of the program (13 further weeks). The children who were not proficient decoders at $\mathrm{t} 2(n=15)$ continued receiving three 20-minute reading sessions and one 30-minute language session per week for the remainder of the program (13 further weeks).

All sessions were designed to allow modelling of target skills, guided practice, repeated exposure, rich interactions and opportunities for independent use. Example lesson plans are provided in Appendix 1 and each of the three components are described below. Researchers who were familiar with the local context checked that the materials were suitable for the rural community and adapted the materials if necessary. All sessions were administered during the school day outside of the classroom. Children in the intervention group received four sessions a 
week delivered over 27 weeks between October 2017 and October 2018. Children in the waiting control group received lessons as normal during this time. Following 27 weeks of interventions sessions and immediately after post-test, the children in the waiting control group began the program and received four sessions a week delivered over 20 weeks due to funding constraints. Child attendance was monitored throughout the program.

\section{Intervention Components}

\section{Reading component}

Reading sessions were completed on a one-to-one basis and targeted basic reading skills; letter knowledge, phoneme awareness, understanding of the sound-letter relationships, sight word reading and reading practice. Before starting, tutors were trained to assess participants' pre-literacy and reading skills in order to determine the sounds, letters, and level of phonological awareness that each child needed to work on. Each session, tutors selected activities from a bank of resources. Every session, the child practiced linking letters and sounds and completed some simple writing activities to reinforce these. Importantly, they also practiced reading connected text using books at a level appropriate for their reading ability, determined by a reading accuracy of at least $94 \%$ on a particular book (Clay, 1985; Hatcher et al., 1994). Teachers made a running record of the child's reading in order to check that the book was selected to be at the appropriate level. They also used this record during lesson preparation to decide upon a teaching point to target in the next lesson.

\section{Language component}

Language sessions were delivered to groups of two students and aimed to promote vocabulary and narrative skills through story discussion and retelling following the successful use of these strategies in educationally disadvantaged contexts (Fricke, Bowyer-Crane, Haley, 
Hulme, \& Snowling, 2013; Fricke et al., 2017). Lessons plans were scripted, but tutors were encouraged to use comments, questions, feedback, and support to maintain appropriate responsiveness. The children were taught vocabulary based around a selected book in which five tier-2 words (Beck \& McKeown, 2007) would appear across topics and content-areas from each book, the same book being presented across three consecutive sessions (Beck \& McKeown, 2007; Beck, McKeown, Sinatra, \& Loxterman, 1991). To encourage narrative skills, children participated in rich discussion about the book and were prompted to retell the story. During discussions, children were asked literal and inferential questions and engaged in conversation about the story elements. When retelling, children were frequently audio-recorded and encouraged to self-monitor their attempts by paying attention to the story elements and words that they had used to connect the ideas. Then, they were prompted to improve their retelling by including missing elements and/or words to connect the ideas. Tutors transcribed audiorecordings of children's narratives and used these to decide on appropriate teaching points for the next lesson.

\section{Reciprocal teaching component}

To support the development of reading comprehension and strategies, competent decoders took part in reciprocal teaching sessions (after Palinscar \& Brown, 1984), based on the successful use of these by poor comprehenders in the effective program evaluated by Clarke et al., (2010). These sessions took place in groups of two students and were child-led with support from the tutor. In these sessions, children practiced the use of four taught strategies (predicting, summarizing, questioning and clarifying) while reading books designed for this component (Global Education Systems Connectors Reciprocal Reading books). As recommended by 
(Reutzel, Smith, \& Fawson, 2005), the strategies were introduced together rather than sequentially.

\section{Tutor Training}

All intervention sessions were delivered by four native Chilean Speech Language Therapists; these professionals had a strong background in child language but training included essential background to ensure knowledge of how language is a foundation for learning to read within the Framework of the Simple View of Reading. Following this, and a review of evidencebased approaches to literacy instruction, more specific training was given on how to implement the program, to use the manual and to assess and monitor progress before the intervention began. Training lasted 25 hours and consisted of presentations by the first author and sessions explaining the program's components and procedures, with delivery modelled. In addition, the tutors performed mock sessions with feedback and created activities for the reading component and lessons for the language component. These activities were created within the framework given and approved by the project leads prior to use.

During the delivery, the tutors received bi-weekly telephone calls from the first author who offered support and discussion as the intervention proceeded. In addition, the island was visited ten times over the course of the program by the senior researchers allowing face-to-face contact and feedback.

\section{Intervention Fidelity}

Ten percent of the sessions were video-recorded and coded by two trained researchers to assess fidelity. Implementation of the program indicators ranged from $87-100 \%$ for the reading component, $73-94 \%$ for the language component, and $83-95 \%$ for reciprocal teaching. Twenty percent of the videos were double coded by the first author to estimate inter-rater agreement (89- 
95\%). Attendance records were used to determine the amount of intervention received per child. On average, in the intervention group, children attended $82 \%$ of available sessions $(\mathrm{SD}=12 \%$, Range $49 \%$ to $100 \%$ ). Non-attendance was due to visits to the Mainland, absence from school and clashes with the school timetabling.

\section{Results}

\section{Analysis Plan}

The main objective of the study was to evaluate the gains made by the intervention group at the end of the program, compared with those of the waiting list control group in the same school. We therefore planned, for each measure, to use analysis of covariance to assess outcome at $\mathrm{t} 3$ controlling for baseline performance at $\mathrm{t} 1$ and additional covariates. We included tests of the interaction with covariates as predictors, proceeding to drop the interaction terms if not significant. Effect sizes were calculated using Cohen's $d$. In addition to analyzing gains for separate measures, we planned to use factor scores to derive reliable constructs of pre-literacy, reading and vocabulary and to subject these to the same analyses. If gains in reading comprehension were significant, we also planned to test the mediators of gains using mediation analysis. Finally, we planned to use mixed effects ANOVAs to assess whether any gains were sustained.

\section{Baseline Reading and Language Skills}

The CLARA study involved 68 children (34 male, 34 female), aged between 4;6 and $14 ; 8$ years at baseline assessment (t1) (mean 8;7, median 8;4, SD 2;7). Despite the age range and the transparency of the Spanish language, many children showed inconsistent letter knowledge and poor phonological awareness. None of the 68 children tested scored full marks on the test of letter knowledge, which assessed knowledge of names, sounds for both capital and small letters. 
The maximum mark was 115 of 129 (89\%) which was obtained by three children (aged 7;9, 9;3 and 10;5). It was noted that children often added vowel sounds onto the letter forms and frequently confused the sounds for the capital and small letters. Twenty of the 68 children tested (29\%) knew only half of the letter-sound correspondences. Phonological awareness was assessed at the level of phoneme, syllable and rhyme. Children below the sixth grade often struggled with phoneme deletion and blending tasks. Of the 68 children tested, fifteen scored zero (aged $4 ; 6$ to $6 ; 4)$ and $27(40 \%$, aged $4 ; 6$ to $11 ; 10)$ scored less than $50 \%$ indicating poor phonological awareness even among the older children. Eighteen children (26\%, aged 4;6 to $7 ; 4)$ could not read any words at baseline and most kindergarten children could not recognize their own names. For those that could read paragraphs (47 children aged 5;4 to 14;8), fluency was generally good with an average reading rate of 81 words per minute $(\mathrm{SD}=36.5)$ and an average reading accuracy of $96 \%(\mathrm{SD}=3.9 \%$, range $79.7 \%-99.9 \%)$ across the YARC passages at t1.

In contrast to reading-related assessments, the vocabulary skills of the children were generally good. The majority of children above the fourth grade (aged 9 years plus) scored well in the CELF vocabulary (picture-naming) task. On average, across this higher age range, children knew the names of 51 of the 58 pictures tested. However, testers reported that although children had wide vocabularies and enjoyed telling stories, their narratives were often poorly constructed and did not always make sense (personal communication).

\section{Intervention Gains}

Gains between pre-test (t1) and post-test (t3) measures were compared between intervention and waiting control groups for individual measures using analysis of covariance models in Stata (Version 15.1; StataCorp. 2017). In each model, outcomes were predicted from 
the same measure at pre-test (the covariate) and a group dummy code; minimization variables (age, t1 CELF vocabulary, and t1 recalling sentences) were used as additional covariates. Effect sizes were calculated using Cohen's $d$; the difference in gains between groups divided by the pooled pre-test standard deviation (see Morris, 2008). The equality of regression slopes was assessed in all models, by including a group by covariate interaction-term. This interaction was only significant for the pre-literacy factor; for all other measures the interaction terms were trivial in size and omitted from the models. Descriptive statistics for individual measures, effect sizes of observed gains (t1 to t3) and measures of consistency are reported in Table 1.

\section{$\langle$ Table 1 about here $>$}

To simplify analyses and increase power, pre- and post-test factor scores were constructed using exploratory factor analyses. Three factors were formed; pre-literacy skills (phoneme awareness and letter knowledge), word reading (one-minute word reading, picture word matching reading test and nonword reading), and vocabulary (CELF and WISC vocabulary, receptive vocabulary, and bespoke vocabulary). In all cases, clear 1-factor solutions were provided with substantial and relatively uniform factor loadings. Pre-test factor scores were generated using regression scoring, whereas post-test factor scores employed the Bartlett method (Skrondal \& Laake, 2001). The intervention group showed greater gains on all three factor scores (pre-literacy, word reading and vocabulary) than the waiting control group. For the pre-literacy factor score there was a negative interaction such that children with the strongest skills at pre-test made smaller gains. There was a substantial advantage for the intervention group evaluated at the mean of the covariate (i.e. for children with average or below average initial scores; standardized mean difference between groups $=0.83$ ). 
The intervention group also showed significantly greater gains than the waiting control group on vocabulary factor scores (formed from CELF and WISC vocabulary, receptive vocabulary, and bespoke vocabulary) (difference between groups $=0.34$ [95\% CI 0.17, 0.51], $\mathrm{t}=4.03 \mathrm{p}<0.001$; standardized mean difference between groups $=0.32$ ) with an equivalent pattern for word reading factor scores (formed from one-minute word reading, picture word matching reading test and nonword reading) (difference between groups $=0.27$ [95\% CI 0.08, 0.47], $\mathrm{t}=2.46, \mathrm{p}=0.017$; standardized mean difference between groups $=0.28$ ).

For the individual measures not included in the factor scores, the intervention group showed gains in reading comprehension (difference between groups $=5.88$ [95\% CI 3.25, 8.53], $\mathrm{t}=4.46 \mathrm{p}<0.001 ;$ standardized mean difference between groups=0.498), MLUw (difference between groups $=1.40[95 \% \mathrm{CI}, 0.71,2.10], \mathrm{t}=4.05 \mathrm{p}<0.001 ;$ standardized mean difference between groups $=0.74$ ), and subordination index (difference between groups $=0.35[95 \% \mathrm{CI}$, $0.250 .45], t=7.07 \mathrm{p}<0.001$; standardized mean difference between groups $=1.39)$. No significant gains were seen for listening comprehension, story grammar and spelling (standardized mean difference between groups $=0.09 ;-0.15$ and 0.04 respectively).

\section{Mediation Analyses}

Mediation analysis was employed to further explore the effects of intervention on word reading and vocabulary factor scores and reading comprehension at $\mathrm{t} 3$, after controlling for autoregressive effects of each of these variables at $\mathrm{t} 1$. Analyses were performed in Mplus (Muthén \& Muthén, 2012) using maximum likelihood estimation, with bias corrected bootstrapped confidence intervals; missing data were handled with Full Information Maximum Likelihood estimation (FIML). 
The mediation model provided a good fit to the data (Figure 2). Both word reading and vocabulary factors scores at $\mathrm{t} 3$ independently predicted reading comprehension. Furthermore, the indirect path from intervention to reading comprehension via word reading at t3 was significant $(\beta=0.042$ [95\% CI $0.006,0.094])$ as was the indirect path from intervention to reading comprehension via vocabulary at $\mathrm{t} 3(\beta=0.062[95 \% \mathrm{CI} 0.022,0.107])$. There was also a direct effect of intervention on reading comprehension in the final model $(\beta=0.117, \mathrm{p}=0.001)$ (Figure 2).

\section{$\langle$ Figure 2 about here $>$}

Finally, mixed effects ANOVAs were used to examine trajectories across $t 1, t 3$ and $t 4$ for individual measures. Continued progression to post-test was observed for the one-minute word reading test (Figure 3). For measures of letter knowledge, phoneme awareness, nonword reading, CELF vocabulary and bespoke vocabulary, gains were maintained although no further progression was made following the end of the intervention (Figure 3). Measures of narrative (MLUw and subordination index) and reading comprehension fell back to the starting level after the intervention ceased.

\section{<Figure 3 about here>}

\section{Discussion}

In this study, we developed a language and reading program for Spanish-speaking children from a vulnerable population and evaluated its effectiveness using a randomized controlled trial. Despite the challenging context in which the program was delivered, it produced substantial improvements in language and literacy skills, and, in line with the predictions of the Simple View of Reading, the framework which we used to develop components, these developments each partially mediated significant gains in reading comprehension. Our findings 
provide 'proof in principle' that evidence-based reading and language interventions can be implemented in vulnerable communities where there are low levels of attainment.

At baseline assessment, many children had poor letter-sound knowledge and none of the children were able to provide the letter sounds or names for every symbol. These observations are in line with the conclusions made by Strasser et al. (2018) regarding the application of theoretical models within the Chilean classroom under a busy curriculum. Although emerging policies mean that teachers are now trained to understand that decoding is an important skill in reading development, the "free" nature of the Chilean curriculum may mean that such basic skills are over-looked within post-kindergarten classrooms. Alternatively, in line with previous studies, which show that decoding may be disrupted in children with reading difficulties (Rosas, Escobar, Ramírez, Meneses, \& Guajardo, 2017), these findings may reflect the high level of language difficulties documented within this particular population. Since other studies indicate that home environment (Nag, Vagh, Dulay, \& Snowling, 2019; Strasser \& Lissi, 2009) and socioeconomic factors (Lervåg, Dolean, Tincas, \& Melby-Lervåg, 2019) can affect the trajectory of reading growth, these findings may be further explained by the isolated and rural nature of this population. Whatever the route of mediation, given the multiplicative nature of decoding and listening comprehension within the simple view of reading, our baseline investigations reinforce the need to include basic pre-literacy skills within educational programs even in transparent languages and especially in vulnerable populations with a high incidence of disorder.

Encouragingly, despite the low baseline level, the CLARA program produced substantial improvements in pre-literacy skills, word reading, vocabulary, narrative skills and reading comprehension with effect sizes of a magnitude considered to be of "educational value" (Cohen's d >0.25) for reading, vocabulary and language (What Works Clearing House, 2017). 
For the most part, these improvements were maintained. Gains in reading comprehension were partially mediated by progress in word reading and word knowledge (as measured by vocabulary) consistent with the Simple View of Reading (Hoover \& Gough, 1990). Together the findings add to a body of evidence that multi-componential interventions can improve language and literacy skills of children at risk for low educational attainments (Snowling \& Hulme, 2011). Specifically, we demonstrate that, given sensitive adaptation, intervention programs developed in Western Culture can be effectively applied in other settings, including vulnerable communities (Bekman et al., 2011).

Our findings also support the importance of decoding and oral language skills as a foundation for reading comprehension; those children with the lowest level at entry made the biggest gains as these foundations developed through the program. The direct effect of intervention remained significant after the mediators of word reading and vocabulary were controlled. These findings are in line with those of a computer-based intervention in Central Chile where gains were only significant for those children who started the program with the lowest reading ability (Ponce et al., 2012).

The CLARA program differs from other previous intervention studies in Chile which have tended to focus upon teacher training or have targeted specific skills (Gomez Franco, 2014; Larraín et al., 2012; Pallante \& Kim, 2013; Ponce et al., 2012; Rosas et al., 2017; Strasser \& Lissi, 2009; Strasser et al., 2018; Yoshikawa et al., 2015). The current program used resident tutors who were qualified speech and language therapists circumventing the need for the reskilling of existing teachers or the incorporation of the program into the school day curriculum. Although this specific approach would be difficult to implement on a larger scale without some adaptation, it demonstrates the importance of consistent and regular intervention, which has been 
identified as a problem in previous Chilean studies (Strasser \& Lissi, 2009; Yoshikawa et al., 2015); our findings suggest it would be worth evaluating this program as an approach for use with small groups of children.

CLARA employed a multi-component approach combining training in letter-sound knowledge and phonological awareness (e.g. Catts et al., 2015), graded- and shared-book reading (e.g. Hatcher et al., 1994), narrative skills (e.g. Griffin et al., 2004; Justice et al., 2006), and progressive reading strategies for children who have developed competence with basic-reading skills (e.g. Duke et al., 2011; Hogan et al., 2011; Perfetti et al., 2005). While some of these components overlapped with previous Chilean interventions; Pallante and Kim (2015) targeted decoding, phonology, vocabulary and reading comprehension which were included in both the language and reading components of CLARA, Larrain, Strasser and Lissi (2012) focused upon shared reading sessions, which formed part of the language and reciprocal teaching components, Rosas et al. (2017) concentrated on decoding skills which were incorporated into the reading sessions and Ponce et al. (2012) taught reading strategies which formed part of our language and reciprocal teaching components, the present study covered a greater number of skills across a wider age range. In general, any gains described in these former studies tended to be related to direct outcomes such as decoding and vocabulary rather than reading comprehension. The generalizations observed in the current study illustrate the importance of considering theoretical frameworks and baseline skills in the design of intervention studies.

All materials used in CLARA were developed by Chilean tutors and researchers and were endorsed by teachers and community members and materials that were not seen as engaging by the children were removed from use. This aspect is likely to have contributed to the positive outcomes of CLARA and underline the need for the adaptation and contextualization of 
materials developed in one culture for use in another (Nag et al., 2014). In particular, we found that children preferred books over printed or electronic materials and favored content that was seen as relevant within island-life (e.g. nature-related texts). Although this required redundancy and flexibility within the original program, it allowed a more personalized approach to the intervention as suggested by Aaron et al. (2008) and Francis et al. (2018). Another important feature of the program is that the fidelity of delivery was measured throughout. Self-monitoring tools and mentorship were provided by the research team and may have promoted consistency, as suggested by Strasser and Lissi (2009) and Strasser et al. (2018).

Although significant gains were found within the CLARA program, improvements in expressive language (particularly narrative skills) and reading comprehension waned after the intervention ended. This lack of maintenance likely reflects the withdrawal of the instruction, suggesting that long-term support is needed to facilitate continued progression and generalization. As such, our findings suggest a dichotomy in terms of "learning" and "application"; maintenance of gains in pre-literacy, reading and vocabulary skills suggest that the intervention group had retained the taught information and basic skills were now in place. However, gains in expressive narrative and reading comprehension were not maintained, suggesting that the gained knowledge was not effectively applied. One possibility is that it is hard to generalize vocabulary gains to wider language use or to serve reading comprehension (Wright \& Cervetti, 2017). It is also possible that the summer break (more than 10 weeks between $\mathrm{t} 3$ and $\mathrm{t} 4$ ) contributed to diminished progression (Allington et al., 2010). An alternative interpretation is that gains were not maintained within the classroom curriculum, underlining the need for ongoing reinforcement of learnt skills in the classroom, as voiced by Strasser et al. (2018). Speculatively, a reduction in active one-to-one encouragement from the tutors may lead 
to regression if generalization strategies are not fully embedded into classroom practice, and may be magnified where the genetic propensity for literacy problems is high.

This study has limitations that should be noted. The first was its small sample size, constrained by the size of population in the location and family's willingness to sign up for their children to participate. Our study therefore had low power, it follows that there is a risk that some findings may be spurious and replication is therefore required. Second, the program was delivered to children spanning a wide age range from 6 to 14 years; while not ideal methodologically, because of the individualized protocols, this did not pose difficulties of implementation. Finally, the costs were considerable: trained professionals delivered the program on a daily basis, a situation that is unusual in remote settings. Nonetheless, the positive gains associated with this trial offer 'proof in principle' of efficacy and indicate that it would be worthwhile to adapt the program into a more sustainable package for delivery in vulnerable communities. The study also confronted issues during implementation including access to the island, limited or ineffective communication with the community, frequent changes of school staff and management and varying degrees of engagement. These factors are part of the reality of working with an vulnerable community and need to be considered within any future intervention designs.

Notwithstanding these problems, this study found support for the simple-view of reading as a basis for the design of multi-component intervention programs in vulnerable populations and developing countries. The study makes a distinctive contribution to the understanding of effective interventions for Spanish-speakers and generates implications for how theoretical frameworks can be used to encourage language and literacy development in vulnerable communities. Findings add to evidence that programs with a focus on pre-literacy skills, oral 
language and reading strategies can produce educationally significant improvements in reading and language outcomes. If sustained, the program has the potential to address the fourth of the Sustainable Development Goals and close the academic gap frequently observed between children in developing countries and those in more advantaged settings. 


\section{Acknowledgments}

This research was funded by ESRC:CONICYT Newton Research Partnership: "A language and reading intervention program for Chile, piloted in the Robinson Crusoe Island" (ES/N01913X/1, PI Dianne Newbury). Ethical approval was granted by Oxford University Research Ethics Committee (R42391/RE001).

The views presented in this work do not represent those of the federal government, nor do they endorse any products or findings presented herein.

We are grateful to the Municipality, school, teachers, children and families who participated in the study, Loreto Aliaga-Salas for help with intervention and project materials, and Denise Cripps for help with logistics. We thank GL Assessment for permission to translate the York Assessment of Reading for Comprehension (YARC) into Spanish. We are grateful to Global Education Systems for giving permission to translate the Connectors Reciprocal Reading books into Spanish.

\section{Conflicts of Interest}

The authors declare no conflicts of interest. 


\section{References}

Aaron, P., Joshi, R. M., Gooden, R., \& Bentum, K. E. (2008). Diagnosis and treatment of reading disabilities based on the component model of reading: An alternative to the discrepancy model of LD. Journal of Learning disabilities, 41(1), 67-84.

doi:10.1177/0022219407310838

Allington, R. L., McGill-Franzen, A., Camilli, G., Williams, L., Graff, J., Zeig, J., . . Nowak, R. (2010). Addressing summer reading setback among economically disadvantaged elementary students. Reading Psychology, 31(5), 411-427.

doi:10.1080/02702711.2010.505165

Beck, I. L., \& McKeown, M. G. (2007). Increasing young low-income children's oral vocabulary repertoires through rich and focused instruction. The Elementary School Journal, 107(3), 251-271. doi:10.1086/511706

Beck, I. L., McKeown, M. G., Sinatra, G. M., \& Loxterman, J. A. (1991). Revising social studies text from a text-processing perspective: Evidence of improved comprehensibility. Reading research quarterly, 26(3), 251-276. doi:10.2307/747763

Bekman, S., Aksu-Koç, A., \& Erguvanl1-Taylan, E. (2011). Effectiveness of an intervention program for six-year-olds: a summer-school model. European Early Childhood Education Research Journal, 19(4), 409-431. doi:10.1080/1350293X.2011.623508

Bishop, D. V., \& Snowling, M. J. (2004). Developmental dyslexia and specific language impairment: same or different? Psychol Bull, 130(6), 858-886. doi:10.1037/00332909.130.6.858

Brigstocke, S., Moll, K., \& Hulme, C. (2016). Test of Basic Arithmetic \& Numeracy Skills. Oxford, UK: Oxford University Press. 
Cain, K., \& Oakhill, J. V. (1999). Inference making ability and its relation to comprehension failure in young children. Reading and Writing, 11(5-6), 489-503. doi:10.1023/A:1008084120205

Caravolas, M., Lervåg, A., Mikulajová, M., Defior, S., Seidlová-Málková, G., \& Hulme, C. (2019). A Cross-Linguistic, Longitudinal Study of the Foundations of Decoding and Reading Comprehension Ability. Scientific Studies of Reading, 1-17. doi:10.1080/10888438.2019.1580284

Caravolas, M., Lervåg, A., Mousikou, P., Efrim, C., Litavský, M., Onochie-Quintanilla, E., .. . Mikulajová, M. (2012). Common patterns of prediction of literacy development in different alphabetic orthographies. Psychological science, 23(6), 678-686. doi:10.1177/0956797611434536

Carroll, J. M., Bowyer-Crane, C., Duff, F. J., Hulme, C., \& Snowling, M. J. (2011). Developing language and literacy: Effective intervention in the early years: John Wiley \& Sons.

Castles, A., Rastle, K., \& Nation, K. (2018). Ending the reading wars: Reading acquisition from novice to expert. Psychological Science in the Public Interest, 19(1), 5-51. doi:10.1177/1529100618772271

Catts, H. W., Herrera, S., Nielsen, D. C., \& Bridges, M. S. (2015). Early prediction of reading comprehension within the simple view framework. Reading and Writing, 28(9), 14071425. doi:10.1007/s11145-015-9576-X

Chapman, R., \& Miller, J. (1984). SALT: Systematic analysis of language transcripts. Wisconsin, USA: University of Wisconsin Press. 
Clarke, P. J., Snowling, M. J., Truelove, E., \& Hulme, C. (2010). Ameliorating children's reading-comprehension difficulties: A randomized controlled trial. Psychological science, 21(8), 1106-1116. doi:10.1177/0956797610375449

Clay, M. M. (1985). The early detection of reading difficulties. Portsmouth, NH: Heinemann Educational Books Inc.

Corcoran, R. P., Cheung, A. C., Kim, E., \& Xie, C. (2018). Effective universal school-based social and emotional learning programs for improving academic achievement: A systematic review and meta-analysis of 50 years of research. Educational Research Review, 25, 56-72. doi:10.1016/j.edurev.2017.12.001

De Barbieri, Z., Fernandez, M. A., Newbury, D. F., \& Villanueva, P. (2018). Family aggregation of language impairment in an isolated Chilean population from Robinson Crusoe Island. Int J Lang Commun Disord, 53(3), 643-655. doi:10.1111/1460-6984.12377

Dilnot, J., Hamilton, L., Maughan, B., \& Snowling, M. J. (2017). Child and environmental risk factors predicting readiness for learning in children at high risk of dyslexia. Development and psychopathology, 29(1), 235-244. doi:10.1017/S0954579416000134

Duff, F. J., \& Clarke, P. J. (2011). Practitioner Review: Reading disorders: what are the effective interventions and how should they be implemented and evaluated? Journal of Child Psychology and Psychiatry, 52(1), 3-12. doi:doi.org/10.1111/j.1469-7610.2010.02310.x

Duke, N. K., Pearson, P. D., Strachan, S. L., \& Billman, A. K. (2011). Essential elements of fostering and teaching reading comprehension. What research has to say about reading instruction, 4, 286-314. doi:10.1598/0829.03 
Flórez-Romero, R., Restrepo, M.-A., \& Schwanenflugel, P. (2009). Promoción del alfabetismo inicial y prevención de las dificultades en la lectura: una experiencia pedagógica en el aula de preescolar. Avances en Psicología latinoamericana, 27(1), 79-96.

Florit, E., \& Cain, K. (2011). The simple view of reading: Is it valid for different types of alphabetic orthographies? Educational Psychology Review, 23(4), 553-576. doi:10.1007/s10648-011-9175-6

Foorman, B. R., Breier, J. I., \& Fletcher, J. M. (2003). Interventions aimed at improving reading success: An evidence-based approach. Developmental neuropsychology, 24(2-3), 613639. doi:10.1080/87565641.2003.9651913

Francis, D. J., Kulesz, P. A., \& Benoit, J. S. (2018). Extending the Simple View of Reading to Account for Variation Within Readers and Across Texts: The Complete View of Reading (CVR i). Remedial and special education, 39(5), 274-288.

doi:10.1177/0741932518772904

Fricke, S., Bowyer-Crane, C., Haley, A. J., Hulme, C., \& Snowling, M. J. (2013). Efficacy of language intervention in the early years. Journal of Child Psychology and Psychiatry, 54(3), 280-290. doi:10.1111/jcpp.12010

Fricke, S., Burgoyne, K., Bowyer-Crane, C., Kyriacou, M., Zosimidou, A., Maxwell, L., .. . Hulme, C. (2017). The efficacy of early language intervention in mainstream school settings: a randomized controlled trial. Journal of Child Psychology and Psychiatry, 58(10), 1141-1151. doi:10.1111/jcpp.12737

García, J. R., \& Cain, K. (2014). Decoding and reading comprehension: A meta-analysis to identify which reader and assessment characteristics influence the strength of the 
relationship in English. Review of educational research, 84(1), 74-111.

doi:10.3102/0034654313499616

Gomez Franco, L. E. (2014). Exploring teachers' read-aloud practices as predictors of children's language skills: the case of low-income Chilean preschool classrooms. Boston College. Lynch School of Education,

Gough, P. B., \& Tunmer, W. E. (1986). Decoding, reading, and reading disability. Remedial and special education, 7(1), 6-10. doi:10.1177/074193258600700104

Griffin, T. M., Hemphill, L., Camp, L., \& Wolf, D. P. (2004). Oral discourse in the preschool years and later literacy skills. First language, 24(2), 123-147. doi:10.1177/0142723704042369

Gutierrez-Clellen, V. F., \& Hofstetter, R. (1994). Syntactic complexity in Spanish narratives: A developmental study. Journal of Speech, Language, and Hearing Research, 37(3), 645654. doi:10.1044/jshr.3703.645

Guzmán, M. M. P., Tirapegui, C. J. C., \& Landaeta, M. M. (2012). El Desarrollo narrativo en niños: una propuesta práctica para la evaluación y la intervención en niños con trastorno del lenguaje. Barcelona, Spain: Ars Médica.

Hatcher, P. J., Hulme, C., \& Ellis, A. W. (1994). Ameliorating early reading failure by integrating the teaching of reading and phonological skills: The phonological linkage hypothesis. Child development, 65(1), 41-57. doi:10.2307/1131364

Heilmann, J., Miller, J. F., Nockerts, A., \& Dunaway, C. (2010). Properties of the narrative scoring scheme using narrative retells in young school-age children. American Journal of Speech-Language Pathology, 19(2), 154-166. doi:10.1044/1058-0360(2009/08-0024) 
Hjetland, H., Lervåg, A., Lyster, S.-A., Hagtvet, B., Hulme, C., \& Melby-Lervåg, M. (2018). Pathways to Reading Comprehension: A Longitudinal Study From 4 to 9 Years of Age. Journal of Educational Psychology, 111(5), 751-763. doi:10.1037/edu0000321

Hogan, T., Bridges, M. S., Justice, L. M., \& Cain, K. (2011). Increasing higher level language skills to improve reading comprehension. Focus on Exceptional Children, 44(3), 1-20. doi:10.17161/fec.v44i3.6688

Høien-Tengesdal, I., \& Høien, T. (2012). The reading efficiency model: An extension of the componential model of reading. Journal of Learning disabilities, 45(5), 467-479. doi:10.1177/0022219411432688

Høien-Tengesdal, I. (2010). Is the simple view of reading too simple? Scandinavian Journal of Educational Research, 54(5), 451-469. doi:10.1080/00313831.2010.508914

Hoover, W. A., \& Gough, P. B. (1990). The simple view of reading. Reading and Writing, 2(2), 127-160. doi:10.1007/BF00401799

Hulme, C., Nash, H., Gooch, D., Lervag, A., \& Snowling, M. (2015). The Foundations of Literacy Development in Children at Familial Risk of Dyslexia. Psychol Sci, 26(12), 1877-1886. doi:10.1177/0956797615603702

Hulme, C., Zhou, L., Tong, X., Lervåg, A., \& Burgoyne, K. (2019). Learning to read in Chinese: Evidence for reciprocal relationships between word reading and oral language skills. Developmental science, 22(1), e12745. doi:doi: 10.1111/desc.12745

Joshi, R. M., Tao, S., Aaron, P., \& Quiroz, B. (2012). Cognitive component of componential model of reading applied to different orthographies. Journal of Learning disabilities, 45(5), 480-486. doi:10.1177/0022219411432690 
Justice, L. M., Bowles, R. P., Kaderavek, J. N., Ukrainetz, T. A., Eisenberg, S. L., \& Gillam, R. B. (2006). The index of narrative microstructure: A clinical tool for analyzing school-age children's narrative performances. American Journal of Speech-Language Pathology, 15(2), 177-191. doi:10.1044/1058-0360(2006/017)

Kim, Y.-S. G. (2017). Why the simple view of reading is not simplistic: Unpacking component skills of reading using a direct and indirect effect model of reading (DIER). Scientific Studies of Reading, 21(4), 310-333. doi:10.1080/10888438.2017.1291643

Kremer, M., Brannen, C., \& Glennerster, R. (2013). The challenge of education and learning in the developing world. Science, 340(6130), 297-300. doi:10.1126/science.1235350

LAC Reads Capacity Program. (2016). Early Grade Reading in Latin America and the Caribbean: A Systematic Review. Retrieved from

Larraín, A., Strasser, K., \& Lissi, M.-R. (2012). Lectura compartida de cuentos y aprendizaje de vocabulario en edad preescolar: un estudio de eficacia. Estudios de Psicología, 33(3), 379-383. doi:10.1174/021093912803758165

Lervåg, A., Dolean, D., Tincas, I., \& Melby-Lervåg, M. (2019). Socioeconomic Background, Nonverbal IQ, and School Absence Affects the Development of Vocabulary and Reading Comprehension in Children Living in Severe Poverty. Developmental science, e12858. doi:10.1111/desc. 12858

Lervåg, A., Hulme, C., \& Melby-Lervåg, M. (2018). Unpicking the developmental relationship between oral language skills and reading comprehension: It's simple, but complex. Child development, 89(5), 1821-1838. doi:10.1111/cdev.12861 
Leyva, D., \& Skorb, L. (2017). Food for thought: Family food routines and literacy in Latino kindergarteners. Journal of Applied Developmental Psychology, 52, 80-90. doi:10.1016/j.appdev.2017.07.001

Martin, N. A., \& Brownell, R. (2012). Receptive One-Word Picture Vocabulary Test-4 (ROWPVT-4). Novato, CA: Academic Therapy Publications.

McCardle, P., \& Chhabra, V. (2004). The voice of evidence in reading research. Baltimore, MD, US: Paul H Brookes Publishing Co.

Megherbi, H., Seigneuric, A., \& Ehrlich, M.-F. (2006). Reading comprehension in French 1st and 2nd grade children: Contribution of decoding and language comprehension. European Journal of Psychology of Education, 21(2), 135. doi:10.1007/BF03173573

Mendive, S., Weiland, C., Yoshikawa, H., \& Snow, C. (2016). Opening the black box: Intervention fidelity in a randomized trial of a preschool teacher professional development program. Journal of Educational Psychology, 108(1), 130. doi:10.1037/edu0000047

Morris, S. B. (2008). Estimating effect sizes from pretest-posttest-control group designs. Organizational research methods, 11(2), 364-386. doi:10.1177/1094428106291059

Mountford, H. S., Villanueva, P., Fernandez, M. A., Barbieri, Z., Cazier, J. B., \& Newbury, D. F. (2019). Candidate gene variant effects on language disorders in Robinson Crusoe Island. Ann Hum Biol, 46(2), 109-119. doi:10.1080/03014460.2019.1622776

Muthén, L., \& Muthén, B. (2012). Mplus - The comprehensive modelling program for applied researchers: User's Guide. Seventh Edition. Los Angeles, CA: Muthén \& Muthén.

Nag, S., Chiat, S., Torgerson, C., \& Snowling, M. J. (2014). Literacy, foundation learning and assessment in developing countries. Retrieved from UK: 
https://www.gov.uk/government/uploads/system/uploads/attachment_data/file/305150/Lit eracy-foundation-learning-assessment.pdf

Nag, S., Snowling, M. J., \& Asfaha, Y. M. (2016). Classroom literacy practices in low-and middle-income countries: an interpretative synthesis of ethnographic studies. Oxford Review of Education, 42(1), 36-54. doi:10.1080/03054985.2015.1135115

Nag, S., Vagh, S. B., Dulay, K. M., \& Snowling, M. J. (2019). Home language, school language and children's literacy attainments: A systematic review of evidence from low-and middle-income countries. Review of Education, 7(1), 91-150. doi:10.1002/rev3.3130

Nation, K. (2019). Children's reading difficulties, language, and reflections on the simple view of reading. Australian Journal of Learning Difficulties, 24(1), 47-73. doi:10.1080/19404158.2019.1609272

National Reading Panel. (2000). Teaching children to read: An evidence-based assessment of the scientific research literature on reading and its implications for reading instruction. Retrieved from USA: https://www.nichd.nih.gov/sites/default/files/publications/pubs/nrp/Documents/report.pdf

Opel, A., Ameer, S. S., \& Aboud, F. E. (2009). The effect of preschool dialogic reading on vocabulary among rural Bangladeshi children. International Journal of Educational Research, 48(1), 12-20. doi:doi.org/10.1016/j.ijer.2009.02.008

Pallante, D. H., \& Kim, Y.-S. (2013). The effect of a multicomponent literacy instruction model on literacy growth for kindergartners and first-grade students in Chile. International Journal of Psychology, 48(5), 747-761. doi:10.1080/00207594.2012.719628

Pavez, M. M., Coloma, C., \& Maggiolo, M. (2008). El desarrollo narrativo en niños: EDNA. Barcelona: Ars Medica. 
Pavez, M. M., Coloma, C., Maggiolo, M., Martínez, L., \& Romero, L. (2002). Procedimientos para evaluar discurso. PREDI. Santiago de Chile: Ediciones Universidad Católica de Chile.

Peralta, M. V. (2011). Early childhood education and public care policies in Chile: A historical perspective to analyze the present. International Journal of Child Care and Education Policy, 5(1), 17.

Perfetti, C. A., Landi, N., \& Oakhill, J. (2005). The acquisition of reading comprehension skill. In M. J. Snowling \& C. Hulme (Eds.), The science of reading: A handbook (pp. 227-247). Malden, MA: Blackwell Publishing Ltd.

Ponce, H. R., López, M. J., \& Mayer, R. E. (2012). Instructional effectiveness of a computersupported program for teaching reading comprehension strategies. Computers \& Education, 59(4), 1170-1183. doi:10.1016/j.compedu.2012.05.013

Quinn, J. M., Wagner, R. K., Petscher, Y., \& Lopez, D. (2015). Developmental relations between vocabulary knowledge and reading comprehension: A latent change score modeling study. Child development, 86(1), 159-175. doi:10.1111/cdev.12292

Raven, J. C., \& Court, J. H. (1998). Raven's progressive matrices and vocabulary scales. Oxford, UK: Oxford pyschologists Press.

Reutzel, D. R., Smith, J. A., \& Fawson, P. C. (2005). An evaluation of two approaches for teaching reading comprehension strategies in the primary years using science information texts. Early Childhood Research Quarterly, 20(3), 276-305.

doi:10.1016/j.ecresq.2005.07.002

Rosas, R., Escobar, J.-P., Ramírez, M.-P., Meneses, A., \& Guajardo, A. (2017). Impact of a computer-based intervention in Chilean children at risk of manifesting reading 
difficulties/Impacto de una intervención basada en ordenador en niños chilenos con riesgo de manifestar dificultades lectoras. Infancia y Aprendizaje, 40(1), 158-188. doi:10.1080/02103702.2016.1263451

San Francisco, A. R., Arias, M., Villers, R., \& Snow, C. (2006). Evaluating the impact of different early literacy interventions on low-income Costa Rican kindergarteners. International Journal of Educational Research, 45(3), 188-201. doi:10.1016/j.ijer.2006.11.002

Schulz, K. F., Altman, D. G., \& Moher, D. (2010). CONSORT 2010 statement: updated guidelines for reporting parallel group randomised trials. BMC medicine, $8(1), 18$. doi:10.1186/1741-7015-8-18

Semel, E. M., Wiig, E. H., Secord, W., \& Langdon, H. W. (2006). CELF 4: Clinical Evaluation of Language Fundamentals 4: Spanish Edition. San Antonio, TX: PsychCorp.

Skrondal, A., \& Laake, P. (2001). Regression among factor scores. Psychometrika, 66(4), 563575. doi:10.1007/BF02296196

Snowling, M. J., \& Hulme, C. (2011). Evidence-based interventions for reading and language difficulties: Creating a virtuous circle. British Journal of Educational Psychology, 81(1), 1-23. doi:10.1111/j.2044-8279.2010.02014.x

Snowling, M. J., Stothard, S. E., Clarke, P., Bowyer-Crane, C., Harrington, A., Truelove, E., . . . Hulme, C. (2009). YARC York Assessment of Reading for Comprehension Passage Reading. London, UK: GL Publishers.

Stahl, S. A., \& Fairbanks, M. M. (1986). The effects of vocabulary instruction: A model-based meta-analysis. Review of educational research, 56(1), 72-110. doi:10.3102/00346543056001072 
Strasser, K., \& Lissi, M. R. (2009). Home and Instruction Effects on Emergent Literacy in a Sample of Chilean Kindergarten Children. Scientific Studies of Reading, 13(2), 175-204. doi:10.1080/10888430902769525

Strasser, K., Mendive, S., Vergara, D., \& Darricades, M. (2018). Efficacy of a self-monitoring tool for improving the quality of the language environment in the preschool classroom. Early Education and Development, 29(1), 104-124. doi:10.1080/10409289.2017.1287992

Tobia, V., \& Bonifacci, P. (2015). The simple view of reading in a transparent orthography: The stronger role of oral comprehension. Reading and Writing, 28(7), 939-957. doi:10.1007/s11145-015-9556-1

Torppa, M., Georgiou, G. K., Lerkkanen, M.-K., Niemi, P., Poikkeus, A.-M., \& Nurmi, J.-E. (2016). Examining the simple view of reading in a transparent orthography: A longitudinal study from kindergarten to grade 3. Merrill-Palmer Quarterly (1982-), 62(2), 179-206. doi:10.13110/merrpalmquar1982.62.2.0179

van Bergen, E., Snowling, M. J., de Zeeuw, E. L., van Beijsterveldt, C. E., Dolan, C. V., \& Boomsma, D. I. (2018). Why do children read more? The influence of reading ability on voluntary reading practices. Journal of Child Psychology and Psychiatry, 59(11), 12051214. doi: $10.1111 /$ jcpp. 12910

Villanueva, P., Nudel, R., Hoischen, A., Fernandez, M., Simpson, N., Gilissen, C., . . Newbury, D. (2015). Exome sequencing in an admixed isolated population indicates NFXL1 variants confer a risk for specific language impairment. PLoS Genet, 11(3), e1004925. doi:10.1371/journal.pgen.1004925

Wechsler, D. (2003). Wechsler intelligence scale for children-Fourth Edition (WISC-IV). San Antonio, TX: The Psychological Corporation. 
What Works Clearing House. (2017). Standards handbook (Version 4.0). Retrieved from Princeton, NJ: https://ies.ed.gov/ncee/wwc/Docs/referenceresources/wwc_standards_handbook_v4.pdf

Whitehurst, G. J., \& Lonigan, C. J. (1998). Child development and emergent literacy. Child development, 69(3), 848-872. doi:10.1111/j.1467-8624.1998.tb06247.x

Wright, T. S., \& Cervetti, G. N. (2017). A systematic review of the research on vocabulary instruction that impacts text comprehension. Reading research quarterly, 52(2), 203-226. doi:10.1002/rrq.163

Yoshikawa, H., Leyva, D., Snow, C. E., Treviño, E., Barata, M., Weiland, C., .. . D'Sa, N. (2015). Experimental impacts of a teacher professional development program in Chile on preschool classroom quality and child outcomes. Developmental psychology, 51(3), 309. doi:10.1037/a0038785 
Table 1. Descriptive statistics for the intervention and waiting control groups

\begin{tabular}{|c|c|c|c|c|c|c|c|}
\hline \multirow[t]{2}{*}{ Measure } & \multirow{2}{*}{$\begin{array}{l}\text { Time } \\
\text { Point }^{\mathrm{a}}\end{array}$} & \multicolumn{2}{|c|}{$\begin{array}{l}\text { Waiting control } \\
\text { group }\end{array}$} & \multicolumn{2}{|c|}{$\begin{array}{l}\text { Intervention } \\
\text { group }\end{array}$} & \multirow{2}{*}{$\begin{array}{l}\text { Effect } \\
\text { Size }^{\mathrm{b}}\end{array}$} & \multirow{2}{*}{ Reliability $^{\mathrm{c}}$} \\
\hline & & $\mathrm{M}$ & $S D$ & $\mathrm{M}$ & $S D$ & & \\
\hline Letter knowledge & Time 1 & 72.9 & 38.9 & 73.9 & 36.5 & $0.61 \dagger \dagger$ & 0.99 \\
\hline \multirow[t]{3}{*}{ (ELDEL; Caravolas et al., 2012) } & Time 2 & 77.1 & 37.4 & 94.6 & 28.3 & & 0.99 \\
\hline & Time 3 & 91.7 & 34.4 & 116 & 22.2 & & 0.99 \\
\hline & Time 4 & 118.6 & 13.1 & 118.8 & 8.6 & & 0.94 \\
\hline Phoneme awareness & Time 1 & 16.5 & 11.9 & 17.7 & 11.8 & $0.85 \dagger \dagger$ & 0.96 \\
\hline \multirow[t]{3}{*}{ (ELDEL; Caravolas et al., 2012) } & Time 2 & 39.1 & 19.5 & 43.4 & 18.4 & & 0.95 \\
\hline & Time 3 & 41.1 & 19.0 & 52.6 & 10.5 & & 0.94 \\
\hline & Time 4 & 55.5 & 8.2 & 54.8 & 9.2 & & 0.88 \\
\hline Picture Word Matching Reading Test & Time 1 & 24.0 & 20.5 & 27.3 & 21.0 & 0.08 & 0.66 \\
\hline \multirow{2}{*}{ (ELDEL; Caravolas et al., 2012) } & Time 2 & 28.5 & 22.3 & 33.5 & 21.1 & & 0.86 \\
\hline & Time 3 & 34.0 & 21.1 & 39.1 & 20.1 & & 0.99 \\
\hline One-minute word reading test & Time 1 & 51.1 & 40.3 & 50.4 & 40.4 & $0.33 \dagger$ & 0.72 \\
\hline \multirow{3}{*}{ (ELDEL; Caravolas et al., 2012) } & Time 2 & 56.1 & 43.8 & 63.6 & 40.8 & & 0.99 \\
\hline & Time 3 & 61.8 & 44.5 & 74.1 & 37.7 & & 0.99 \\
\hline & Time 4 & 73.9 & 36.2 & 82.5 & 35.7 & & 0.99 \\
\hline Nonword Reading & Time 1 & 28.7 & 23.5 & 31.1 & 24.2 & $0.20 \dagger$ & 0.81 \\
\hline \multirow{3}{*}{ (ELDEL; Caravolas et al., 2012) } & Time 2 & 33.7 & 25.9 & 39.8 & 24.4 & & 0.79 \\
\hline & Time 3 & 37.2 & 23.7 & 44.5 & 21.3 & & 0.99 \\
\hline & Time 4 & 43.5 & 19.7 & 50.9 & 21.3 & & 0.97 \\
\hline Spelling & Time 1 & 7.7 & 5.6 & 8.9 & 5.6 & 0.18 & 0.93 \\
\hline \multirow[t]{2}{*}{ (ELDEL; Caravolas et al., 2012) } & Time 3 & 15.3 & 10.0 & 17.6 & 9.8 & & 0.91 \\
\hline & Time 4 & 17.9 & 9.1 & 19.8 & 8.6 & & 0.92 \\
\hline CELF vocabulary & Time 1 & 42.6 & 10.3 & 41.0 & 12.9 & $0.52 \dagger \dagger$ & 0.79 \\
\hline \multirow{2}{*}{ (Semel et al., 2006) } & Time 3 & 54.3 & 10.1 & 58.9 & 11.7 & & 0.88 \\
\hline & Time 4 & 59.2 & 8.1 & 57.4 & 11.4 & & 0.86 \\
\hline WISC vocabulary & Time 1 & 16.6 & 8.9 & 16.7 & 8.35 & $0.23 \dagger$ & 0.79 \\
\hline \multirow{2}{*}{ (translated fromWechsler, 2003) } & Time 3 & 17.5 & 10.0 & 19.6 & 9.7 & & 0.86 \\
\hline & Time 4 & 21.9 & 10.6 & 22.3 & 11.6 & & 0.73 \\
\hline \multirow{2}{*}{$\begin{array}{l}\text { Receptive vocabulary (ROWPVT; translated } \\
\text { from Martin \& Brownell, 2012) }\end{array}$} & Time 1 & 80.0 & 14.8 & 80.3 & 16.1 & 0.007 & 0.76 \\
\hline & Time 3 & 86.3 & 10.5 & 86.7 & 10.1 & & 0.84 \\
\hline \multirow[t]{3}{*}{ Bespoke Vocabulary } & Time 1 & 9.9 & 5.4 & 11.4 & 5.2 & $0.57 \dagger \dagger$ & 0.82 \\
\hline & Time 3 & 13.0 & 6.9 & 17.4 & 8.3 & & 0.87 \\
\hline & Time 4 & 18.0 & 6.7 & 17.4 & 8.5 & & 0.84 \\
\hline Listening Comprehension & Time 1 & 10.6 & 2.9 & 11.2 & 3.4 & -0.06 & 0.70 \\
\hline \multirow{2}{*}{ (EDNA; Pavez et al., 2008) } & Time 3 & 12.2 & 2.3 & 12.7 & 2.0 & & 0.43 \\
\hline & Time 4 & 14.5 & 2.6 & 14.2 & 1.8 & & 0.45 \\
\hline MLU-w & Time 1 & 6.7 & 1.8 & 7.2 & 1.9 & $0.54 \dagger \dagger$ & - \\
\hline \multirow[t]{2}{*}{ (collected from PREDI; Pavez et al., 2002) } & Time 3 & 6.8 & 1.1 & 8.4 & 1.7 & & - \\
\hline & Time 4 & 7.5 & 1.5 & 7.2 & 1.5 & & - \\
\hline Subordination Index & Time 1 & 1.2 & 0.2 & 1.3 & 0.2 & $1.20 \dagger \dagger \dagger$ & - \\
\hline \multirow[t]{2}{*}{ (collected from PREDI; Pavez et al., 2002) } & Time 3 & 1.1 & 0.2 & 1.5 & 0.3 & & - \\
\hline & Time 4 & 1.3 & 0.2 & 1.6 & 0.2 & & - \\
\hline Story Grammar & Time 1 & 6.5 & 2.5 & 6.2 & 2.3 & -0.04 & - \\
\hline (collected from PREDI; Pavez et al., 2002) & Time 3 & 7.2 & 2.3 & 6.7 & 2.5 & & - \\
\hline & Time 4 & 6.9 & 1.9 & 6.9 & 2.1 & & - \\
\hline Reading Comprehension & Time 1 & 13.4 & 12.2 & 13.8 & 11.6 & $0.51 \dagger \dagger$ & 0.86 \\
\hline (YARC; translated from Snowling et al., 2009) & Time 3 & 16.2 & 12.3 & 22.8 & 12.9 & & 0.83 \\
\hline & Time 4 & 15.1 & 11.5 & 15.2 & 12.4 & & 0.84 \\
\hline Non-verbal IQ (RAVEN; Raven \& Court, 1998) & Time 1 & 24.2 & 7.9 & 24.9 & 8.1 & & - \\
\hline Recalling Sentences (Semel et al., 2006) & Time 1 & 58.7 & 21.4 & 57.0 & 19.0 & 0.18 & 0.91 \\
\hline Arithmetic (TOBANS; Brigstocke et al., 2016) & Time 1 & 46 & 19.7 & 40.6 & 22.9 & & - \\
\hline
\end{tabular}


${ }^{\text {a }}$ Data from $\mathrm{t} 4$ should be interpreted with caution as the assessors were no longer blind to group allocation and the waiting control group had received seven fewer weeks than the intervention group due to funding constraints and time restrictions.

${ }^{\mathrm{b}}$ Cohen's d values are $\dagger=$ small, $\uparrow \dagger=$ medium, and $\dagger \dagger \dagger=$ large.

${ }^{\mathrm{c}}$ Internal consistency was estimated using Cronbach's alpha. 


\section{Figure Legends}

Figure 1. Consort Diagram Showing Participant Flow.

Diagram follows the updated guidelines for reporting Randomized Control Trials (Schulz et al., 2010).

Figure 2. Mediation Model Showing the Impact of the Intervention on Reading Comprehension. Indirect effects of intervention on reading comprehension via word reading and vocabulary are significant. The model shows a good fit to the data: $\chi 2=7.34, p=0.39, \operatorname{RMSEA}=0.027[0.00$, 0.158], $\mathrm{CFI}=0.999, \mathrm{SRMR}=0.021$.

Figure 3. Maintained group trajectories.

(a) Phoneme awareness, (b) Letter Knowledge, (c) One-minute word reading test, (d) Nonword reading, (e) CELF vocabulary, (f) Bespoke vocabulary

Mean scores at pretest (t1), posttest (t3) and delayed posttest (t4) for the intervention and waiting control groups. Error bars represent $95 \%$ Confidence Intervals. Data from t4 should be interpreted with caution as the assessors were no longer blind to group allocation and the waiting control group had received seven fewer weeks than the intervention group due to funding constraints and time restrictions. 